\title{
SEX DIFFERENTIALS IN MORBIDITY AND MORTALITY RISKS EXAMINED BY AGE AND CAUSE IN THE SAME COHORT
}

\author{
DEBORAH L. WINGARD, ${ }^{1}$ BARBARA A. COHN," GEORGE A. KAPLAN, ${ }^{3}$ \\ PIERA M. CIRILLO," AND RICHARD D. COHEN ${ }^{-2}$
}

\begin{abstract}
Wingard, D. L. (Dept. of Community and Family Medicine, U. of California, San Diego, La Jolla, CA 92093-0607), B. A. Cohn, G. A. Kaplan, P. M. Cirillo, and R. D. Cohen. Sex differentials in morbidity and mortality risks examined by age and cause in the same cohort. Am J Epidemiol 1989;130:601-10.

Many studies indicate that women live longer than men but report more physical illness. This report is the first prospective study of sex ratios for morbidity and mortality due to a variety of causes in a single cohort: a random sample of 5,239 adults, aged 30 years or older in 1965, who have been followed through 1983 (19 years) by cause and age. For both cancer incidence and mortality there was a female excess before age 50 years, followed by a male excess peaking between ages 60 and 69 years. Sex ratios for ischemic heart disease mortality, on the other hand, indicated a male excess at virtually all ages, and that these sex ratios declined with age. However, three measures of heart disease morbidity (selfreported chest pain, heart trouble, and high blood pressure) demonstrated a female excess that did not vary by age. All four measures of functional disability (impaired self-care, impaired mobility, cessation of work, and reduction of work) demonstrated a female excess that did not vary by age (with the exception of a male excess in impaired self-care in adults aged 30 to 39 years). Further analyses of sex differences in health need to acknowledge the heterogeneity of the relation of sex to disease, and the complex age-sex interaction that varies remarkably with both cause and manifestation of outcome (morbidity vs. mortality).
\end{abstract}

heart diseases; mortality; neoplasms; risk; sex ratio

One of the most striking patterns in epidemiology is the marked sex differential in mortality (1-5). In the United States, women live longer than men and they have lower death rates at virtually every age and for most causes $(1,3-5)$. In 1980 , the age-

Received for publication July 29,1988 , and in final form January 31, 1989.

${ }^{1}$ Department of Community and Family Medicine, University of California, San Diego, La Jolla, CA.

" Human Population Laboratory, California Public Health Foundation, Berkeley, CA.

${ }^{3}$ Human Population Laboratory, California Department of Health Services, Berkeley, CA.

Reprint requests to Dr. Deborah I. Wingard, Department of Community and Family Medicine, M007, University of California, San Diego, La Jolla, CA 92093-0607.

This research was supported by the National Institute on Aging Grant no. R01-AG05687. adjusted mortality ratio between men and women was 1.8-men had nearly an 80 per cent higher age-adjusted death rate than women-life expectancy at birth was 77.5 years for women and 70.0 years for men (6). This female advantage in life expectancy existed even at age 80 years at which time women had 8.6 more years expected and men 6.7 years (6). Our understanding of these striking differences in mortality is complicated by an equally striking but opposite pattern for physical morbidity $(1,3,7)$.

Interpretation of this apparent contradiction-that women live longer than men but experience more physical illness-is complicated by several factors. First, it has been proposed that women's greater rate of 
illness may reflect their greater utilization of medical services and physicians' diagnostic patterns, as well as women's greater willingness to acknowledge and report illness (1, 3, 8-10). A female excess of illness persists, however, when physical examinations are used for assessment in populationbased samples and when pregnancy-related conditions are removed (1). In addition, two reviews of analyses of reporting behavior concluded that while underreporting of illnesses was common, there was little evidence of sex differences in such underreporting $(1,11)$.

The apparent contradiction between sex differentials in morbidity and mortality may also reflect differences in study design and resultant differences in measures of morbidity and mortality. Specifically, vital statistics data provide mortality rates $(1,3)$ while population-based studies provide mortality risks $(12,13)$. Cross-sectional data (e.g., surveys) provide morbidity prevalence rates $(3,7)$, while longitudinal data provide information on incidence and/or prevalence. Prevalence measures reflect incidence and survival; for example, the female excess for morbidity may reflect sex differences in survival and/or sex differences incidence. Additionally, estimates of risk are not always comparable to estimates of rates (14).

Sex differences in morbidity and mortality based on different samples may also reflect geographic, ethnic, and age differences between the samples, and different time periods covered, as well as true sex differences. For example, since the sex differentials in mortality have demonstrated secular trends $(1,5,15)$, comparisons across populations at different points in time may not reflect a true contradiction. Data have demonstrated a significant variation in the sex ratio of both morbidity $(1,3,5)$ and mortality $(1-6,15)$ by age. Therefore, the apparent contradiction between sex differences in morbidity and mortality may be a function of differences in the age structure of the samples studied and whether data are presented by age-specific categories or are age-adjusted to different standard populations.

Finally, it has been suggested that there really is no contradiction between sex differentials in morbidity and mortality. Rather, women have higher morbidity for conditions that rarely cause death, such as rheumatoid arthritis, whereas men tend to have more fatal conditions, such as coronary heart disease $(1,7,8,16)$. While this may be true for overall morbidity and mortality, there is still a question as to whether there is a contradiction in morbidity and mortality for specific diseases. For example, based on 1979 National Health and Nutrition Examination Survey (NHANES) data (7), men reported more coronary heart disease than women while women reported equivalent or greater amounts of cerebrovascular disease. However, in 1980 there was a male excess of mortality for both of these disease categories (6).

Using a general measure for morbidity, women report more disability than men (3). Again, this may reflect a higher prevalence of nonfatal chronic disease in women, or a longer survival for women with chronic disease, both of which result in more disability. Thus the analysis of sex differences in functional disability is crucial to understanding the apparent contradiction between sex ratios for morbidity and mortality.

This presentation focuses on the descriptive epidemiology of sex ratios for morbidity and mortality for the two leading causes of death in the United States, heart disease and cancer, and for two general measures of health, functional disability and all cause mortality. To our knowledge, this is the first study of sex differences in new functional disability, new morbidity, and mortality based on a single cohort over the same time period.

\section{Materials and METHods}

\section{Study population}

The study sample consists of 5,239 adults aged 30 years or older who participated in 
a 1965 survey of physical, social, and psychologic indicators of health conducted by the Human Population Laboratory of the California Department of Health Services. The sample procedure, explained in greater detail elsewhere (17), elicited an 86 per cent response rate to the mail questionnaire. The male and female response rates were virtually equal ( 85 per cent and 87 per cent, respectively). When compared with respondents, the small group of nonrespondents included slightly more older people and whites, and retired, single, and widowed persons. However, the differences between respondents and nonrespondents have a negligible effect on population estimates, and respondents have been judged to be a representative sample of adults in Alameda County, California (18). The present analysis is restricted to the 2,424 men and 2,815 women who were 30 years old or older in 1965, 84 per cent of whom were white.

\section{Morbidity ascertainment}

Cancer. Cancer incidence through 1983 was ascertained via automated record linkage between the Human Population Laboratory data from the 1965 survey and the population-based cancer incidence files (California Tumor Registry) maintained by the Cancer Prevention Section of the State of California Department of Health Services. This on-going population-based tumor registry has been maintained in Alameda County since 1960, and was expanded to the five counties comprising the San Francisco-Oakland Standard Metropolitan Statistical Area in 1969. Ascertainment of newly diagnosed cancers for this geographic area is estimated to be 98 per cent complete (19). It should be noted that while cancer incidence ascertainment was restricted to respondents still residing in the San Francisco Bay Area, cancer mortality ascertainment was not so restricted. Comparison of incidence with mortality data suggests that underascertainment of incident cases due to out-migration was minimal. Only 6.6 per cent of the cancer deaths occurred among respondents who had moved outside of the San Francisco Bay Area and for whom there was no incident information. Cancer incidence of all sites included melanoma, but not skin cancer. Analyses of cancer incidence excluded persons reporting cancer in 1965.

Heart disease. Nearly 80 per cent of surviving 1965 survey respondents returned a second questionnaire in 1974. Questions on heart disease morbidity assessed high blood pressure, heart trouble, and chest pain occurring during the 12 months preceding the second survey. For heart disease morbidity analyses, all persons with prevalent conditions reported in 1965 were excluded.

Functional disability. The 1974 survey also asked survivors several questions about functional disability of six months or longer duration. These questions covered: 1) work cessation due to illness or injury; 2) work reduction due to illness or injury; 3) impaired self-care (feeding, dressing, or moving around); and 4) impaired mobility (climbing stairs or getting outdoors). Again, all persons reporting similar functional disability in 1965 were excluded from analyses of 1974 disability.

\section{Mortality ascertainment}

Mortality data were collected for the 19year period from 1965 to 1983. Mortality information was obtained via the California Death Registry (20) and extensive in-state and out-of-state tracing procedures. Through these methods, death certificates were obtained for 676 men and 654 women aged 30 years or older in 1965. Underlying cause of death was coded according to the International Classification of Diseases, Injuries, and Causes of Death, Adapted, Eighth Revision (ICDA-8). Ischemic heart disease deaths encompassed ICDA-8 codes 410-414. Because of the small number of cancers for specific sites, all cancers were grouped together. Nineteen-year mortality data are presented for mortality comparisons and for comparisons of cancer morbidity and mortality. Nine-year mortality data are presented for comparison with nine- 
year heart disease morbidity and functional disability.

\section{Statistical analyses}

Simultaneous 95 per cent confidence intervals were calculated for age-specific sex ratios within each outcome (21). This method adjusts confidence limits for multiple comparisons within each outcome.

\section{RESULTS}

Over the 19-year period 1965 to 1983,676 men and 654 women died of all causes, including 148 men and 156 women who died
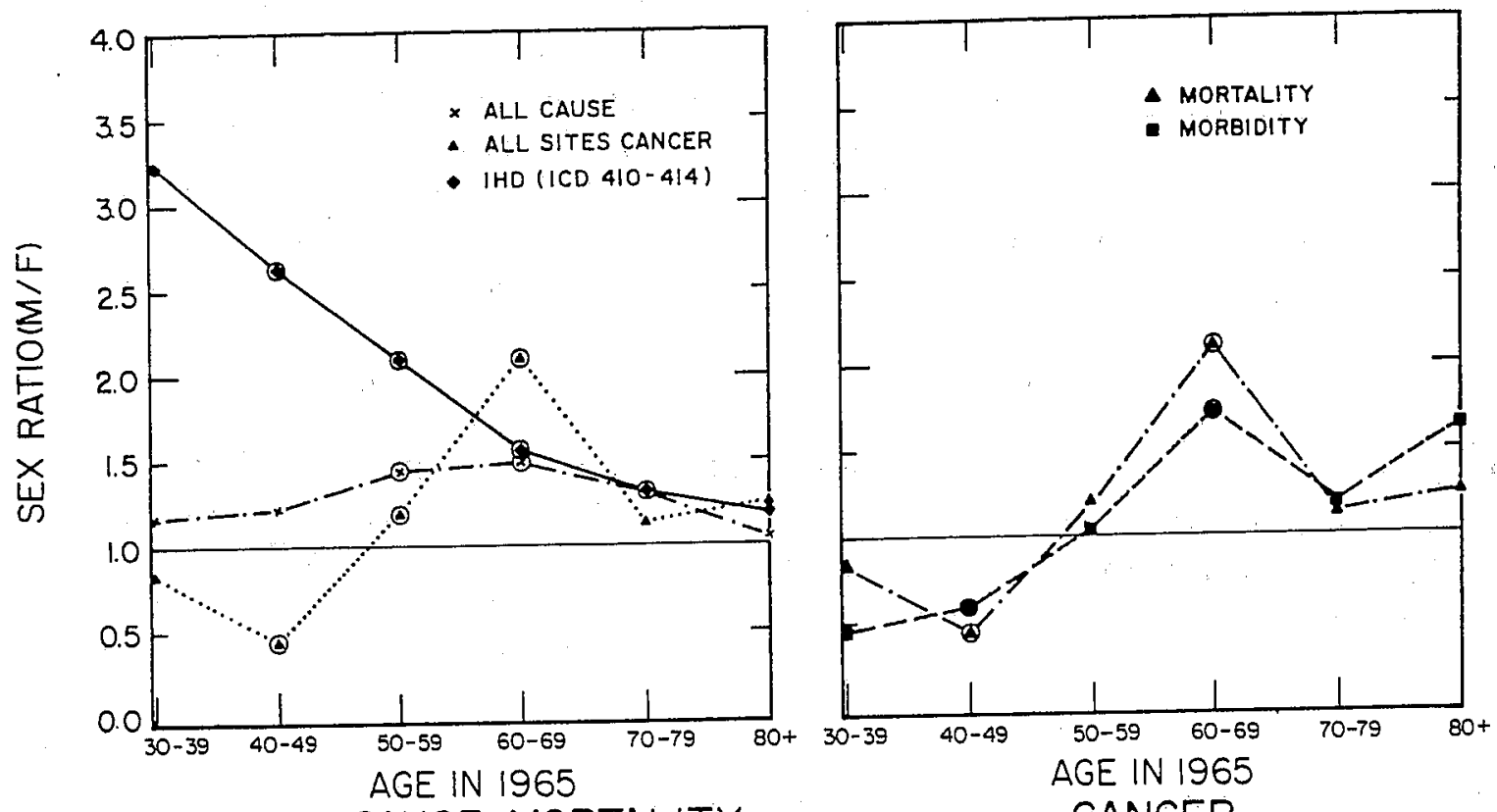

ALL CAUSE MORTALITY

CANCER
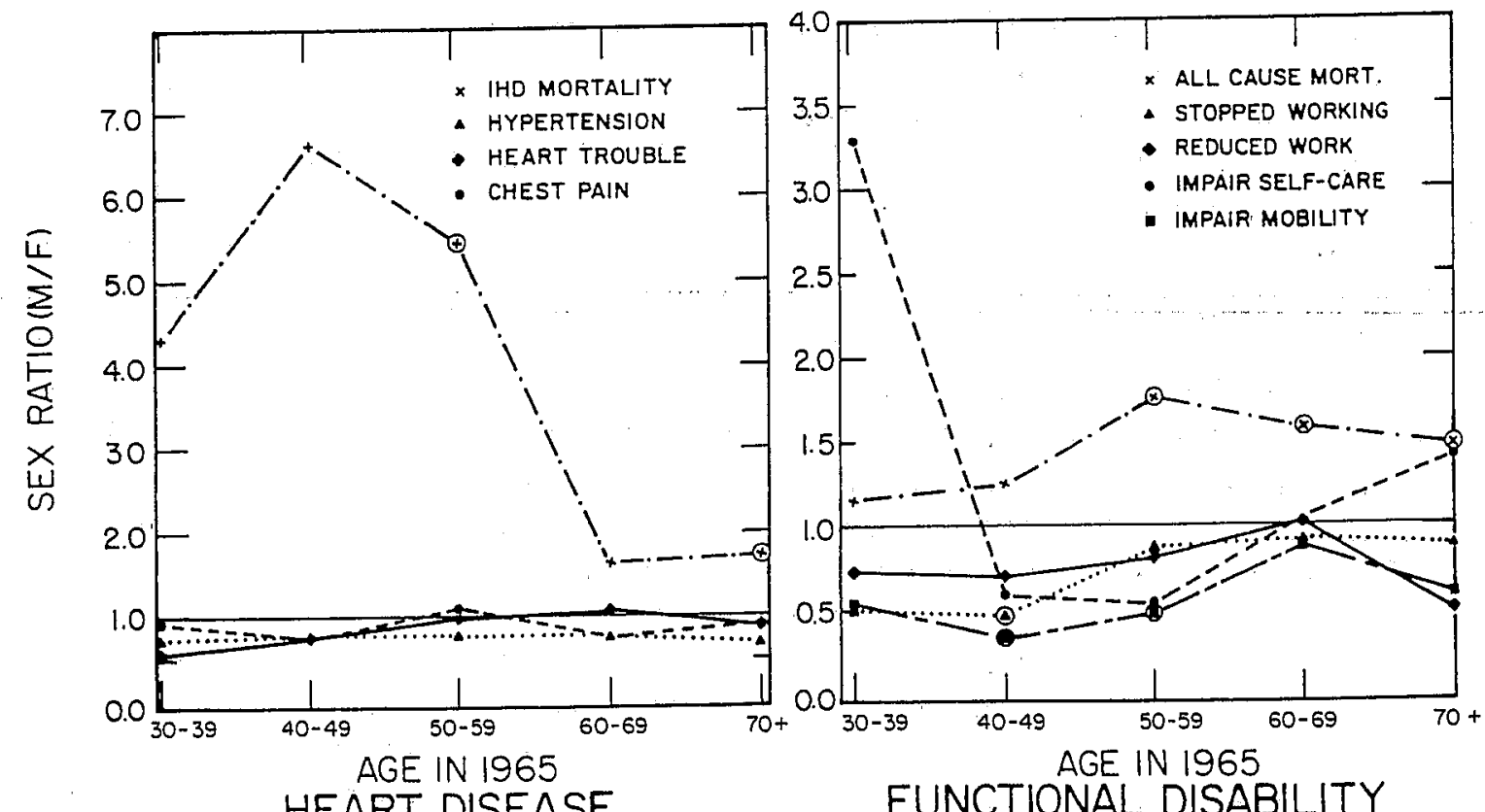

FIGURE 1. Sex ratios for morbidity and mortality by age and cause, Alameda County, California, 1965-1983. Circled values indicate 95 per cent confidence interval does not contain 1.0. All cause mortality and cancer ratios are based on 19 years of follow-up; heart disease and functional disability ratios are based on 9 years of follow-up. For comparability, all cause mortality in the functional disability portion of this illustration is based on 9 years of follow-up. IHD, ischemic heart disease. 
of cancer, and 257 men and 210 women who died of ischemic heart disease. Figure 1 (all cause mortality) presents 19-year agespecific sex mortality ratios for each of the foregoing. There was a male excess at all ages for all cause mortality that peaked in those aged 60-69 years. There was also a male excess at all ages for ischemic heart disease mortality, but the sex ratio declined steadily with age from 3.2 in those aged $30-$ 39 years to 1.2 in those aged 80 years or older. In contrast, there was a female excess for cancer mortality before age 50 years and a male excess thereafter that peaked in those aged 60-69 years.

Figure 1 also allows a comparison of agespecific sex ratios for morbidity and mortality rates from cancer, heart disease, and functional disability. Note that for cancer, age-specific sex ratios for 19-year morbidity and mortality rates followed the same pattern, a female excess before age 50 years, followed by a male excess that peaked at 60-69 years of age.

Sex ratios for nine-year heart disease morbidity and mortality in figure 1 exhibit very different patterns, however. There was a male excess at all ages for ischemic heart disease mortality that declined with age. In contrast, there was a small nonsignificant female excess at most ages for hypertension, heart trouble, and chest pain, with no obvious age pattern.

As shown in figure 1 (functional disability), sex ratios for work cessation, work reduction of six months or longer due to illness or injury, impaired self-care, and impaired mobility of six months or longer duration exhibited a female excess under age 60 years, with the exception of impaired self-care among those aged 30-39 years.

In order to tell if variations in male or female risks with age explain variations in the sex ratio, figure 2 presents age and sexspecific mortality risks. Because figure 2 plots log risk against age, parallel lines between two points represent a constant sex ratio with equivalent acceleration in risk with age for both sexes. The reduction of the sex ratio at older ages for both all
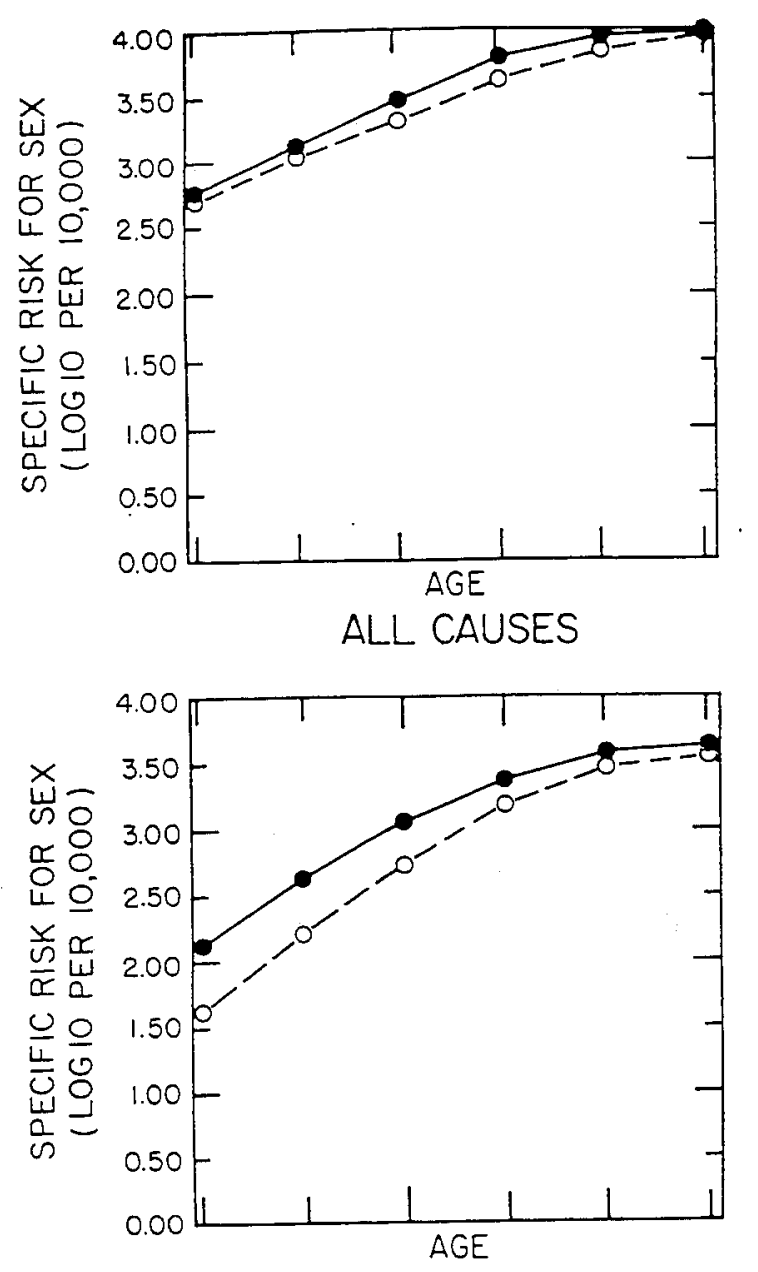

ISCHEMIC HEART DISEASE

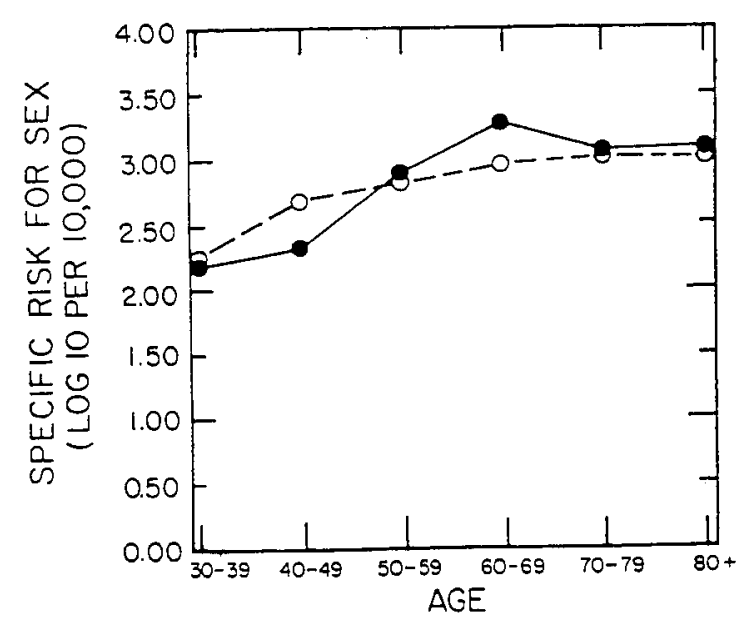

CANCER

FIGURE 2. Sex-specific risks of 19-year mortality by age and cause, Alameda County, California, 19651983. - men; O, women.

cause mortality and heart disease mortality (figure 1) appears due to acceleration of female risk with age with a concomitant deceleration of male risk (figure 2). After 
age 60 years there is a greater deceleration of male than female risk. This pattern is most prominent for heart disease mortality. A different pattern is evident for cancer mortality (figure 2). Before age 50 years, female risk rises more rapidly with age than male risk. Between ages 50 and 60 years, the trend reverses. This pattern produces the female excess in cancer mortality under age 50 years; this pattern then reverses and becomes a male excess which peaks in the 60 - to 69-year age group (figure 1). The convergence of the male and female cancer mortality risks after age 69 years is due to a decline in male rates after age 69 years.

'Similarly, figure 3 presents agè- and sexspecific 19-year morbidity risks for cancer. The age pattern of sex-specific risks are very similar for cancer morbidity (figure 3) and mortality (figure 2). Females have higher risks than males at the youngest ages with very little change in risk with age. Males experience an acceleration of risk with age, peaking at ages 60-69 years and declining thereafter. These patterns produce the complex relation between age and sex ratio for cancer morbidity and mortality shown in figure 1.

Figure 4 presents age- and sex-specific nine-year morbidity and mortality risks for heart disease. As for 19-year ischemic heart disease mortality, nine-year mortality (figure 4) shows a pattern of convergence for

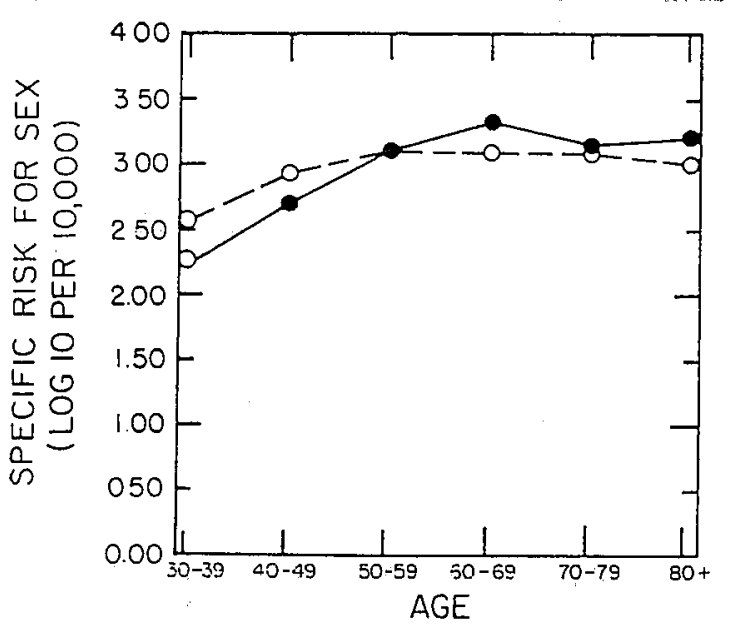

FIGURE 3. Sex-specific risks of 19-year cancer morbidity by age: Alameda County, California, 1965-1983. $\bullet$, men; $O$, women. male and female risks due primarily to accelerated increase in female risk with age and a concomitant deceleration of the increase in male risk with age. In contrast, self-reported high blood pressure, chest pain, and heart trouble do not follow this pattern (figure 4). Male risk for heart disease morbidity rarely exceeds that for females; in fact the sex ratios for these three measures of heart disease morbidity hover close to one.

Finally, figure 5 presents age- and sexspecific nine-year risks of functional disability of six months or longer duration. The convergence at older ages of male and female risks of work cessation appears due to accelerating risk with age in males relative to females. Impaired self-care shows an additional alteration of the sex ratio, reversing from male excess at younger ages to female excess at older ages due to a steeper increase in impairment among young women between ages 30 and 40 years.

\section{Discussion}

This is the first study of sex differences in new functional disability, new morbidity, and mortality in the same population over the same time period. This allows for control of extraneous factors specific to different populations and time intervals which may confound comparison of sex ratios. Reports of new morbidity also permit an assessment of sex differences in risk, as opposed to preexisting morbidity which reflects both risk and survival differences. Prior research suggested an excess prevalence of morbidity among women for conditions that rarely cause death $(1,7,8,16)$, an excess of functional disability among women (3), and excess mortality among men (1-5). The present study, based on a single population, also found an excess of new functional disability among women and an excess of all cause mortality among men. For specific diseases, the present study also confirms a female excess of new morbidity and a male excess of mortality for ischemic heart disease, but not for cancer. 
Numerous mortality studies have demonstrated a male excess for ischemic heart disease $(1-4,7)$, while both the National Health and Nutrition Examination Survey (NHANES) (22) and population-based studies such as Framingham (23) and Rancho Bernardo (13) reported a female excess in prevalence of hypertension after age 55 or 60 years, and at younger ages a male excess that was less dramatic than for mortality. The findings for cancer are consistent with reports from the Surveillance, Epidemiology, and End Results (SEER) program (24). These reports demonstrate a female excess of both incidence and mortality before age 50 years and a male excess thereafter.

The contrast between sex ratios for ischemic heart disease morbidity and mortality observed in this population is intriguing. The male excess of mortality, but female excess for self-reported morbidity may occur because: 1) women are more perceptive of their health status and, therefore, report illness earlier, before it is life threatening; 2) women report their illnesses earlier due to earlier diagnosis because they are more likely to utilize medical care; 3) women

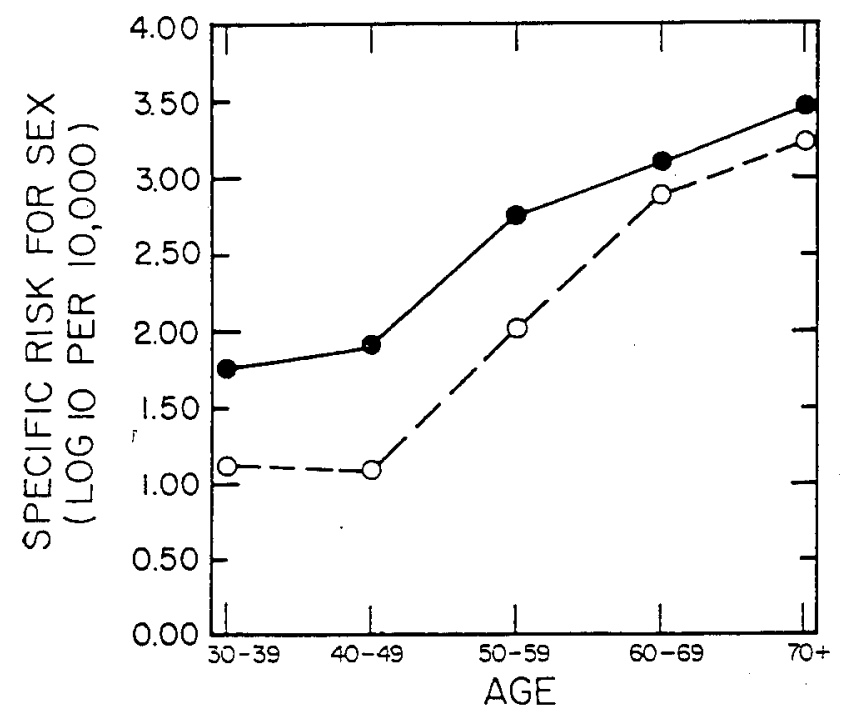

IHD MORTALITY

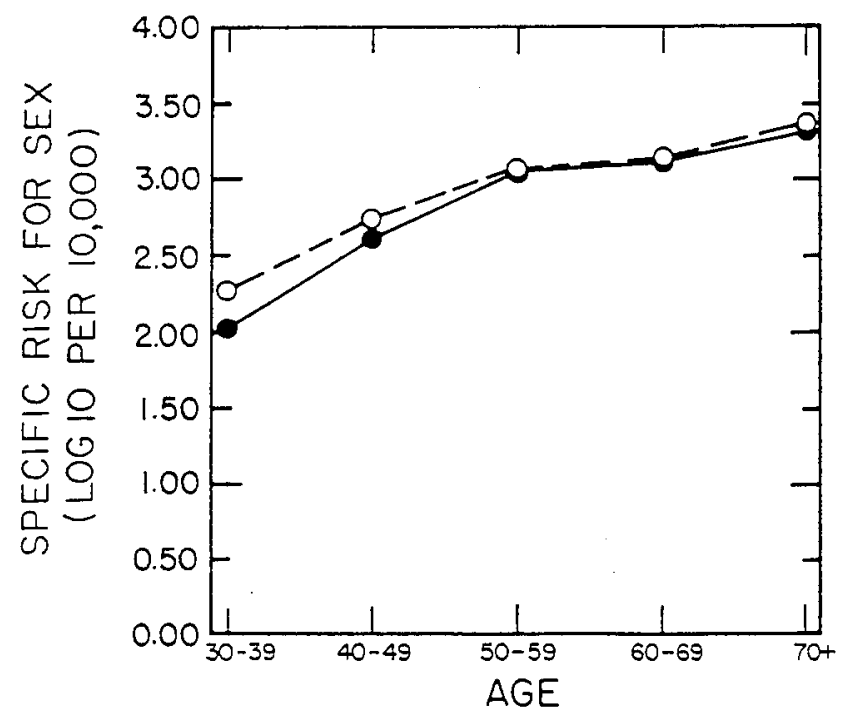

HEART TROUBLE

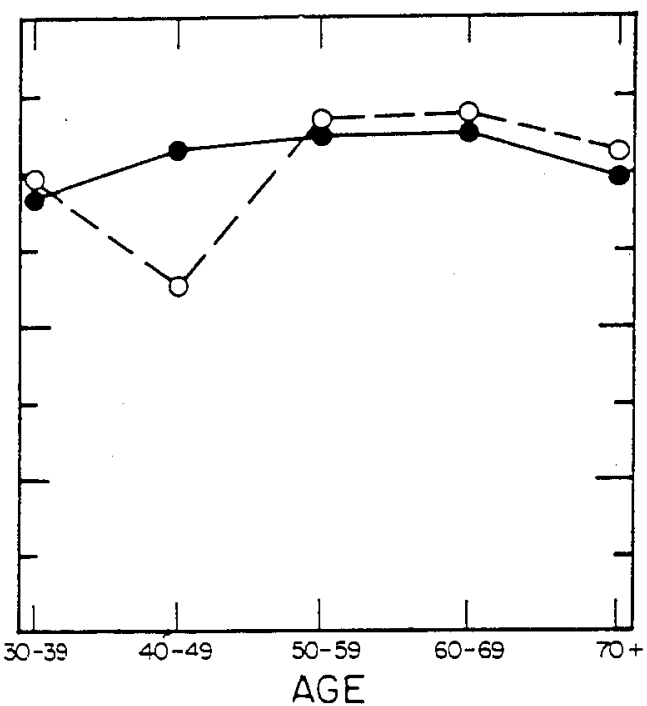

HIGH BLOOD PRESSURE

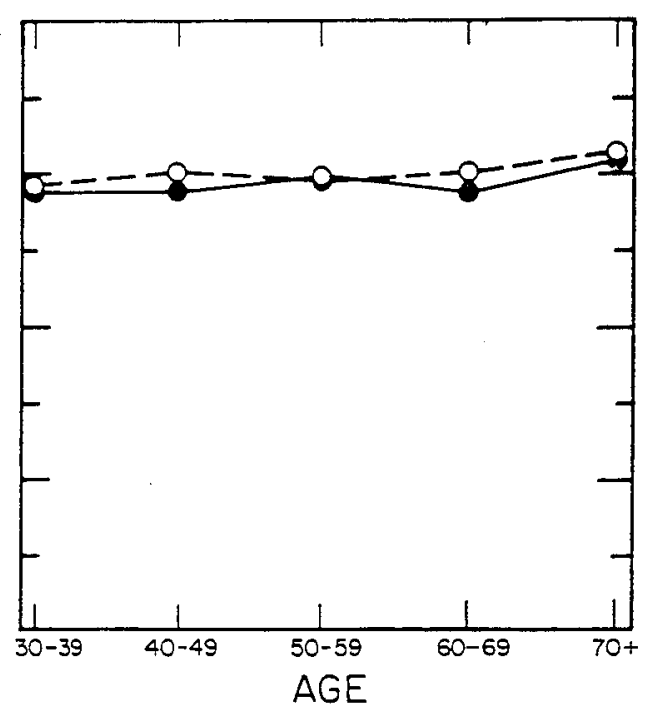

CHEST PAIN

FrguRE 4. Sex-specific risks of 9-year heart disease morbidity and mortality by age, Alameda County, California, 1965-1974. IHD, ischemic heart disease; men; $\bigcirc$, women. 


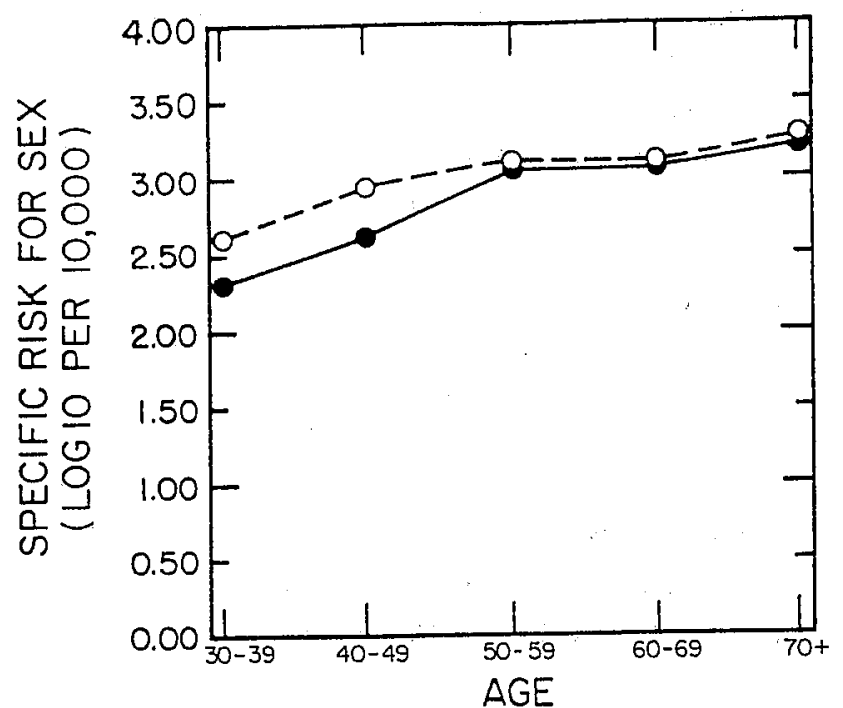

WORK CESSATION

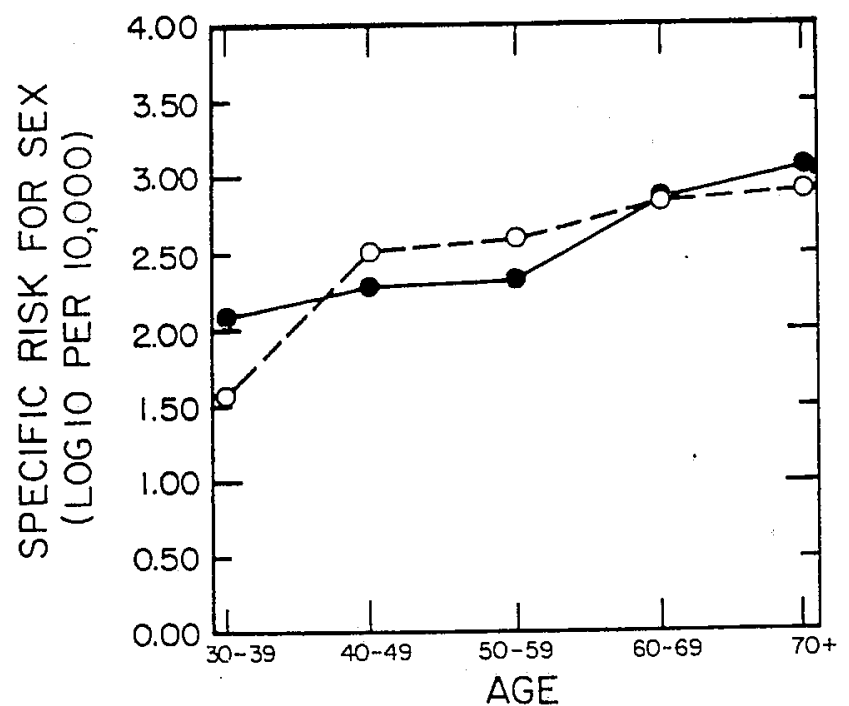

IMPAIRED SELF-CARE

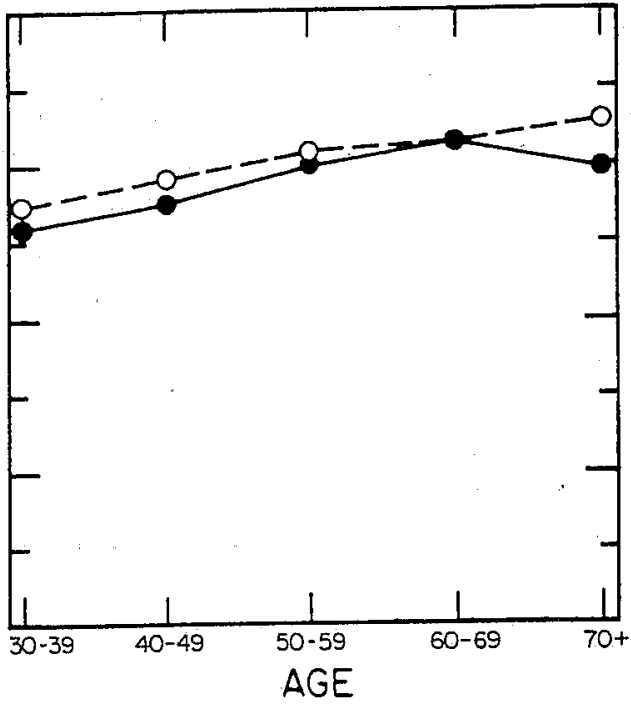

WORK REDUCTION

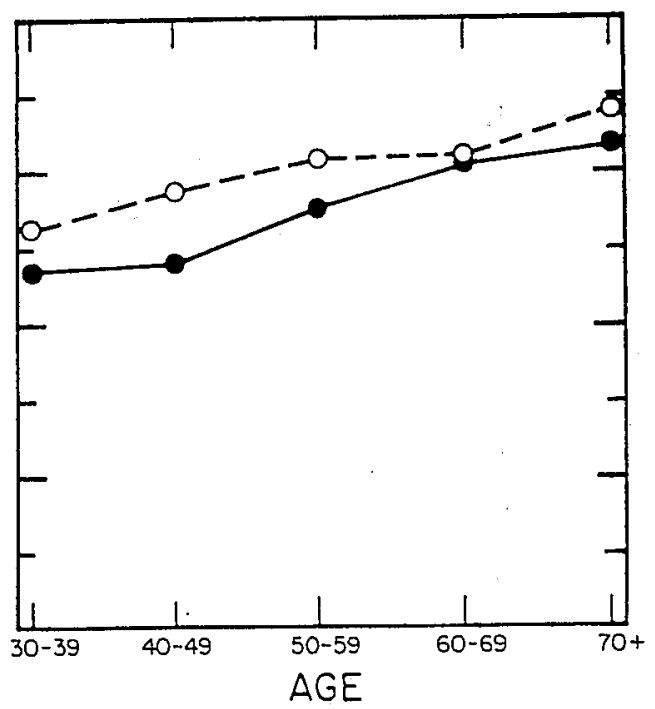

IMPAIRED MOBILITY

FIGURE 5. Sex-specific risks of 9-year functional disability (6 months or longer duration) by age, Alameda County, California, 1965-1974. men; O, women.

have better survival than men for a given level of severity of illness; or, 4) women are reporting different heart disease.

Work is currently in progress to attempt to disentangle these explanations for the contradiction between sex ratios for ischemic heart disease morbidity and mortality. We are examining possible interactions between sex and self-reports of ischemic heart disease morbidity on subsequent mortality. If self-reported morbidity is a stronger predictor for men, we will also examine whether behaviors, medical care utilization, or self-perception of health status can explain this interaction.
Unlike ischemic heart disease, all site cancer morbidity, measured as incidence, and all site cancer mortality have similar sex ratios by age. This suggests that over the nine-year follow-up period examined, there may be little male-female difference in survival. However, since males and females have different sites of cancer (i.e., breast vs. prostate) and since frequency by site differs by sex (24), it is important to study sex differences for site specific cancers which occur in both sexes. In particular, we are currently examining sex ratios for lung cancer mortality and the role of sex differences in the prevalence of ciga- 
rette smoking in explaining the male excess for lung cancer mortality. Having observed a pronounced variation of sex ratios by age for all sites of cancer, it will be necessary to control for age very carefully. It is possible that part of the variation of the sex ratio by age is due to differences in smoking prevalence by sex and birth cohort; however, it is also possible that variations by age reflect age-related biologic processes, or other exposures which differ by age and sex over time.

Similar to the findings for ischemic heart disease, there is also a contradiction between sex ratios for all cause mortality and new functional disability, with a male excess for mortality and female excess or parity with males for functional disability (figure 2). There are important public health consequences of female parity or even excess of functional disability relative to males despite a male excess of all cause mortality. Health and social services may be of particular importance to females to maintain independence and improve quality of life.

The variations of the sex ratio by both age and outcome suggest that one's sex does not have uniform effects in all aspects of human health. Thus, it is an oversimplification to imply that women (or men) are the stronger (or weaker) sex. The findings suggest that serious epidemiologic investigation into the role of sex in disease risk should begin with highly specific investigation by age and by outcome (morbidity vs. mortality by cause).

Moreover, rather than focus solely on the sex ratio in investigating the influence of sex in disease, the findings of this study suggest that the components of the sex ratio, male risk and female risk, should be examined simultaneously to provide clues to disease processes. As shown in figures 2 through 5 , differences in sex ratios by age for the different causes are due to sexspecific variations in risk by age, unique to the outcome studied. For example, the convergence of the sex ratio for ischemic heart disease mortality for older ages is due to accelerations in female risk with age and decelerations of male risk with age (figure 2). This may reflect earlier mortality in susceptible men. In contrast, the same convergence of the sex ratio for cancer mortality in the older age groups is a result of a very different pattern with a leveling off for females and a sharp deceleration for males.

The underlying mechanisms which produce similar sex ratios for cancer and ischemic heart disease mortality at older ages may be very different. Understanding these effects may be crucial to understanding the etiology of these diseases.

\section{REFERENCES}

1. Wingard DL. The sex differential in morbidity, mortality, and lifestyle. Ann Rev Public Health 1984;5:433-58.

2. Lopez $\mathrm{AD}$. The sex differential in mortality in developed countries. In: Lopez AD, Ruzicke LR, eds. Sex differentials in mortality: trends, determinants and consequences. Canberra: Australian National L'niversity Press, 1984:03-120.

3. Verbrugge LM. Gender and health: an update on hypotheses and evidence. $J$ Health Soc Behav 1985;26:156-82.

4. Waldron I. What do we know about causes of sex differences in mortality? A review of the literature. Popul Bull U N 1986;18:59-76.

5. Hazzard WR. Biological basis of the sex differential in longevity. J Am Geriatr Soc 1986;34:45571.

6. National Center for Health Statistics. Advance report, final mortality statistics, 1980. Monthly Vital Stat Rep 1983;32(suppl 4):1-39.

7. National Center for Health Statistics. Sex differences in health and use of medical care, United States, 1979. Hyattsville, MD: National Center for Health Statistics, 1983. (Vital and health statistics, Series 3: Data from the National Health Interview Survey, the National Ambulatory Medical Care Survey, the National Hospital Discharge Survey, no. 24). (DHHS publication no. (PHS)831408).

8. Verbrugge LM. Sex differentials in health. Public Health Rep 1982:97:417-37.

9. Gove WR. Hughes M. Possible causes of the apparent sex differences in physical health: an empirical investigation. Am Sociol Rev 1979;44:12646.

10. Nathanson CA. Sex, illness and medical care: a review of data, theory, and method. Soc Sci Med 1977;11:13-25.

11. Waldron I. Sex differences in illness, incidence, prognosis and mortality: issues and evidence. Soc Sci Med 1983:17:1107-23.

12. Wingard DL. The sex differential in mortality rates: demographic and behavioral factors. Am IJ Epidemiol 1982;115:205-16. 
13. Wingard DL, Suarez L, Barrett-Connor E. The sex differential in mortality from all causes and ischemic heart disease. Am J Epidemiol 1983;117: 165-72.

14. Morgenstern $\mathrm{H}$, Kleinbaum DG, Kupper LL. Measures of disease incidence used in epidemiologic research. Int J Epidemiol 1980;9:97-104.

15. Verbrugge LM. Recent trends in sex mortality differentials in the United States. Women Health 1980;5:17-37.

16. Verbrugge LM. Female illness rates and illness behavior: testing hypotheses about sex differences in health. Women Health 1979;4:61-79.

17. Berkman LF, Breslow L. Health and ways of living: the Alameda County study. New York: Oxford University Press, 1983.

18. Hochstim JR. Health and ways of living-the Alameda County Population Laboratory. In: Kessler I, Levin ML, eds. The community as an epidemiologic laboratory. Baltimore: Johns Hopkins University Press, 1970:149-76.

19. Resource for Cancer Epidemiology, California Department of Health Services. Uterine cancer incidence: San Francisco Bay area, 1960-1975. Berkeley, CA: Resource for Cancer Epidemiology, 1980.
20. Belloc N, Arellano M. Computer record linkage on a survey population. Health Serv Rep 1973; 88:344-50.

21. Gart JJ. The comparison of proportions: a review of significance tests, confidence intervals, and adjustments for stratification. Rev Int Stat Inst 1971;39:148-69.

22. National Center for Heaith Statistics. Hypertension in adults 25-74 years of age, United States, 1971-75. Rockville, MD: National Center for Health Statistics, 1981. (Vital and health statistics, Series 11: Data from the National Health and Nutrition Examination Survey, no. 221). (DHHS publication no. (PHS)81-1671).

23. National Heart Lung and Blood Institute. Means at each examination and inter-examination variation of specified characteristics: Framingham Study, exam 1 to exam 10. Washington DC: $\mathrm{Na}$ tional Heart Lung and Blood Institute, 1973. (The Framingham Study. An epidemiological investigation of cardiovascular disease: data from the Framingham Study, section 29). (DHEW publication no. (NIH)74-478).

24. Young JL, Percy CL, Asire AJ, et al. Cancer incidence and mortality in the United States, 1973-77. NCI Monogr 1981;57:1-1081. 